\title{
Research Paper: The Effect of Educational Intervention on Health Care Providers' Preparedness in the Natural Disasters: A Case Study of Health Care Providers in Shahreza City, Iran
}

\author{
Mandana Sahebzadeh $^{1}$ (D), Abdol Hossein Gherekhloo ${ }^{2 *}$ (D), Golrokh Atighechian ${ }^{1}$ (D) \\ 1. Health Management and Economics Research Center, Isfahan University of Medical Sciences, Isfahan, Iran. \\ 2. Department of Health Services Management, Faculty of Management and Medical Information, Isfahan University of Medical Sciences, Isfahan, Iran.
}

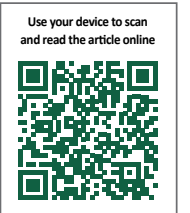

Citation: Sahebzadeh M, Gherekhloo AH, Atighechian G. The Effect of Educational Intervention on Health Care Providers' Preparedness in the Natural Disasters: A Case Study of Health Care Providers in Shahreza City, Iran. Health in Emergencies and Disasters Quarterly. 2020; 6(1):39-46. http://dx.doi.org/10.32598/hdq.6.1.345.1

http://dx.doi.org/10.32598/hdq.6.1.345.1

Article info:

Received: 15 Feb 2020

Accepted: 05 Aug 2020

Available Online: 01 Oct 2020

\section{Keywords:}

Preparedness, Natural disaster, Crisis, Health personnel, Education

\section{A B S T R ACT}

Background: Every year, numerous natural disasters occur around Iran, with many casualties and financial losses. In these crises, the demand for health care suddenly and uncontrollably increases. In such circumstances, the readiness of health centers and their staff is critical in reducing injuries and mortality. This study aimed to determine the effect of disaster preparedness intervention on the attitude, knowledge, and practice of health care providers in Shahreza City, Iran.

Materials and Methods: This one-group quasi-experimental study was conducted on 55 health care providers in Shahreza health centers selected by the census method. The participants completed a researcher-made questionnaire in two stages before and two months after attending a disaster preparedness workshop, a top-table maneuver, and an operational maneuver. The obtained data were analyzed by SPSS V. 23 using descriptive statistics and paired t-test.

Results: Data analysis showed a significant difference between the mean scores of pretraining and posttraining regarding the rate of knowledge, attitude, and preparedness $(\mathrm{P}<0.05)$, but there was no significant difference between the mean scores of performance $(\mathrm{P}>0.05)$.

Conclusion: The intervention significantly improved awareness and developed a positive attitude about disaster preparedness. Although it slightly increased performance, it was not significant. Nonetheless, it appears that the continuation of training along with other operational methods can improve individual performance. It is recommended that disaster preparedness programs be considered as one of the topics of in-service education of health care providers and also as the subject of educational courses in different academic periods. 


\section{Introduction}

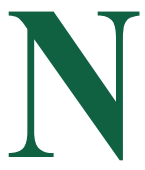

atural disasters have always and for centuries threatened the lives of human societies [1] and have been experienced by humans. They are often uncontrollable and cause disabilities, loss of human lives and property, and severe known and unknown consequences $[2,3]$. Because of the occurrence of natural disasters, all economic, political, and cultural infrastructures are affected, leading to disruption of the functioning of society and widespread human, economic, and environmental effects [4].

The number of deaths due to natural disasters varies significantly from year to year. Natural disasters may occur with very few deaths for some years until a significant disaster kills many people. On average, over the past decade, almost 60000 people died from natural disasters worldwide every year [5].

In 2019, 396 natural disasters occurred worldwide, killing 11755 people, affecting more than 95 million people, and causing total damage of about $\$ 103$ billion. Asia is the most vulnerable continent with about $40 \%$ of natural disasters, $45 \%$ of deaths, and $74 \%$ of all affected people [6].

Iran, which is located in this continent, is considered one of the most accident-prone areas globally due to its geographical location in the Alpine-Himalayan earthquake belt [7]. It is among the ten most vulnerable countries to natural disasters [8], and every year, it experiences many natural disasters associated with several human and substantial financial losses. Out of 40 types of natural disasters globally, 31 types occur in different parts of Iran [9, 10]. Earthquakes, floods, droughts, landslides, and storms are common dangers experienced in Iran every year $[2,11]$. The consequences of these accidents cannot be avoided entirely because some of them are very complex and unpredictable [12]. Apart from the irreparable damage caused by accidents and disasters, lack of prevention and preparation for a proper and effective response can create a painful tragedy [13]. Natural disasters do not automatically lead to catastrophe. What makes disasters catastrophic is the vulnerability of a small number of communities [4]. Therefore, having the preparedness to deal with natural disasters is one of the most critical factors to reduce injuries [14].

In disasters, deaths and complications occur, so the demand for health care suddenly and uncontrollably increases, and people flock to health centers and hospitals [15]. In such circumstances, the readiness of these cen- ters and their staff to provide fast, efficient, and timely services can reduce deaths and increase the number of survivors $[9,16]$. In other words, appropriate emergency health measures can reduce the damage caused by the disaster [17]. The World Health Organization announced preparedness as a long-standing concern and emphasizes the importance of the activities needed to achieve it. One of the main concerns in determining the preparedness of medical centers in disasters is the staff's readiness [18].

Regarding the preparedness of staff, training is an essential factor [19]. Numerous studies have pointed the role of education in preparing and increasing the safety of people against disasters and emergencies [20-24]. Farajzadeh et al. recommended continuous training against accidents and disasters, creating a suitable educational environment, and giving proper motivation to nurses to improve their preparedness [25]. Ghanbari et al. showed that implementing a training program as part of the disaster preparedness process has improved people's preparedness. Also, the implementation of these programs increases personnel awareness of existing programs to deal with disasters, increases employee's participation in planning and elimination of problems, and improves the skills of personnel in performing their tasks [26].

Shahreza City is located in an area with high seismicity, near the Zagros mountain range and on the edge of the fault. On the other hand, a large area of worn-out urban fabric has made the city vulnerable to floods and earthquakes [27]. Because health care providers in the health care network system are in direct contact with the public and in the health reform plan, they are responsible for assessing and educating families about disaster preparedness. In addition to improving the overall preparedness of society in the face of natural disasters, they can enhance the provision of health services and reduce injuries and casualties. In other words, these people, besides having a positive attitude, should be able to show the acquired knowledge in their practice and behavior and be a model for the covered population.

On the other hand, in recent years, health care providers have integrated into the healthcare system, and little information is available regarding their knowledge, attitude, and practice. This study aimed to determine the level of preparedness of people against natural disasters and investigate the effect of educational intervention on the attitude, knowledge, and practice of health care workers in Shahreza. The study results can be used in health-related planning and decision making. 


\section{Materials and Methods}

The present study was a one-group quasi-experimental study using the pre-test/post-test design without a control group. The study population included all health care workers $(n=55)$ working in health centers of Shahreza City, Isfahan Province, Iran. A researcher-made questionnaire was used to collect data. To prepare the questionnaire, we conducted some exploratory analysis, and research in the library, and related articles in reputable scientific databases. The questionnaires used in national and international research and a checklist for assessing family preparedness in disasters of the Ministry of Health were examined. Our questionnaire consisted of 38 questions in four sections. The first part consisted of 8 questions related to the demographic characteristics of the respondents, including age, gender, marital status, level of education, work experience, field of study, and workplace. The second part included 12 questions to examine the knowledge of health care providers about disaster preparedness, which were designed as 4-choice questions and the correct answer scored 1, and the wrong answer scored 0 . Therefore, the total score of the knowledge questionnaire was 12 . The third part included 8 questions to measure the participants' attitude scored on a 5-point Likert scale from "completely disagree" to "strongly agree." Therefore, the maximum score was 40 . The fourth part consisted of 10 questions regarding performance assessed by "yes" and "no" and scored 0 and 1 , respectively. Therefore, the maximum score was 10 . Finally, the readiness scores of individuals consisted of the scores of the three sections of knowledge, attitude, and performance and scored 62 in total.

To verify the validity of the scale, the content validation method was used. Accordingly, the initial questionnaire was sent to 10 health experts in disasters and was reviewed, evaluated, and revised by these people. Then, a pilot study was performed to confirm its reliability. The questionnaire was first completed by 10 health care providers (not selected samples) and had similar conditions to the participants, and it was repeated two weeks later. Finally, its correlation coefficient was calculated to be 0.715. Besides, the Cronbach alpha of the attitude questionnaire was estimated to be 0.72 .
Regarding the performance section, the Kuder-Richardson formula was used, and the obtained score was 0.85 . To collect the data, after making the necessary coordination, we referred to 12 health centers of Shahreza City. After introducing the researcher and explaining the research's purpose, the questionnaire was provided to the samples. While completing the questionnaire, the necessary oral explanations were provided to the respondents, and the researcher was present during all processes. After completing the initial questionnaire, a 2-day workshop was held, in which participants were trained based on educational texts approved by the Ministry of Health. At the end of the second day of the workshop, a top-table maneuver and an operational maneuver for disaster preparedness were held. It consisted of the determination of safe areas, Drop, Cover, and Hold On (DCHO), emergency exit, gathering in the safe area. Then a practical firefighting exercise was carried out with the participation of the samples and the cooperation of the experts of the city fire department. The questionnaire was completed again two months after the intervention. Data were analyzed by SPSS V. 23 using descriptive statistics and paired t-test.

\section{Results}

According to the results obtained from 55 completed questionnaires, 11 respondents $(20 \%)$ were male, and 44 (80\%) were female. Also, $18.2 \%$ had an associate degree, $72.7 \%$ had a bachelor's degree, and $9.1 \%$ of the respondents had a master's degree. The fields of study of participants were as follows: family health, $36.4 \%$; disease prevention, $7.12 \%$; midwifery, $27.3 \%$; environmental health, 5.5\%; occupational health, 5.5\%; mental health, 9.1\%; and laboratory, 3.6\%.

It was also found that 54 cases responded to the age question, and 52 cases responded to the work experience question. The minimum age was 24 , and the maximum was 37 years. The mean age of the participants was 30 years, and their average work experience was 3.58 years (Table 1 ).

Descriptive statistics obtained from the pre-test and post-test were also examined (Table 2).

Table 1 . Descriptive statistics of age and work experience of the participants

\begin{tabular}{|c|c|c|c|c|c|c|}
\hline Variables & No. & Range & Min. & Max. & Mean士SD & Variance \\
\hline Experience & 52 & 5.5 & 1.5 & 7 & $3.58 \pm 1.41$ & 2.007 \\
\hline Age (y) & 54 & 13 & 24 & 37 & $30.35 \pm 3.55$ & 12.610 \\
\hline
\end{tabular}


Table 2. Descriptive indices of variables in the pre-test and post-test stages (No. 55)

\begin{tabular}{|c|c|c|c|c|c|c|}
\hline Variables & Stage & Range & Min. & Max. & Mean£SD & Variances \\
\hline \multirow{2}{*}{ Knowledge } & Pre-test & 7 & 4 & 11 & $7.25 \pm 1.72$ & 2.971 \\
\hline & Post-test & 5 & 7 & 12 & $10.50 \pm 1.31$ & 1.73 \\
\hline \multirow{2}{*}{ Attitude } & Pre-test & 22 & 18 & 40 & $32.78 \pm 4.55$ & 20.76 \\
\hline & Post-test & 11 & 29 & 40 & $34.76 \pm 2.93$ & 8.62 \\
\hline \multirow{2}{*}{ Performance } & Pre-test & 10 & 0 & 10 & $5.49 \pm 3.15$ & 9.95 \\
\hline & Post-test & 10 & 0 & 10 & $5.83 \pm 2.98$ & 8.91 \\
\hline \multirow{2}{*}{ Preparedness } & Pre-test & 32 & 27 & 59 & $45.52 \pm 6.50$ & 42.32 \\
\hline & Post-test & 16 & 43 & 59 & $51.10 \pm 4.57$ & 20.91 \\
\hline
\end{tabular}

Table 3. Non-parametric test to check the normal distribution of variables (No. 55)

\begin{tabular}{cccc}
\hline Variables & Stage & The Kolmogorov-Smirnov Statistic & Approximate Sig. (Bilateral) \\
\hline Knowledge & Pre-test & 1.236 & 0.094 \\
Attitude & Pre-test & 1.097 & 0.180 \\
Performance & Pre-test & 1.036 & 0.234 \\
Preparednesst & Pre-test & 0.567 & 0.905 \\
Knowledge & Post-test & 1.471 & 0.026 \\
Attitude & Post-test & 0.872 & 0.432 \\
Performance & Post-test & 1.239 & 0.093 \\
Preparedness & Post-test & 1.082 & 0.192 \\
\hline
\end{tabular}

In this section, to select the appropriate test, first, the normality of the mean scores of each variable was checked using the Kolmogorov-Smirnov test (Table 3). Because the significance level for all research variables except for the knowledge test is greater than 0.05 , the assumption of normality for all variables except the post-test was valid. However, the sample size was 55. Based on the central lim- it theorem ( the sample size is large $\geq 30$ ), we used the parametric test [28] despite no regular distribution of the variable, to obtain more accurate results. Therefore, the paired t-test was used to compare the mean scores (Table 3).

According to the results of Table 4, the significance level was less than 0.05 . Therefore, the difference between the

Table 4. The mean score of variables in different stages

\begin{tabular}{|c|c|c|c|c|c|c|c|}
\hline \multirow{3}{*}{ Variables } & \multicolumn{4}{|c|}{ Mean Differences } & \multirow{3}{*}{$\mathbf{t}$} & \multirow{3}{*}{ df } & \multirow{3}{*}{$\mathbf{P}$} \\
\hline & \multirow{2}{*}{ Mean $\pm S D$} & \multirow{2}{*}{$\begin{array}{l}\text { Mean Stan- } \\
\text { dard Error }\end{array}$} & \multicolumn{2}{|c|}{ 95\% Confidence Interval } & & & \\
\hline & & & Lower Limit & Upper Limit & & & \\
\hline $\begin{array}{l}\text { Difference between post-test } \\
\text { and pre-test knowledge scores }\end{array}$ & $3.25 \pm 1.96$ & 0.26 & 2.72 & 3.78 & 12.28 & 54 & 0.001 \\
\hline $\begin{array}{l}\text { The difference between } \\
\text { post-test and pre-test attitude } \\
\text { scores }\end{array}$ & $1.98 \pm 5.16$ & 0.69 & 0.58 & 3.37 & 2.84 & 54 & 0.006 \\
\hline $\begin{array}{l}\text { Difference between post-test } \\
\text { and pre-test performance } \\
\text { scores }\end{array}$ & $0.34 \pm 4.50$ & 0.60 & -0.87 & 1.56 & 0.56 & 54 & 0.572 \\
\hline $\begin{array}{l}\text { Difference between post-test } \\
\text { and pre-test preparedness } \\
\text { scores }\end{array}$ & $5.58 \pm 8.31$ & 1.12 & 3.33 & 7.83 & 4.97 & 54 & 0.001 \\
\hline
\end{tabular}


mean scores of knowledge in the pre-test and post-test was significant. The mean scores of health care providers' attitudes after training were significantly higher than before the training $(\mathrm{P}<0.05)$. Regarding the mean score of performance, the significance level $(\mathrm{P}=0.572)$ was greater than the test error $(0.05)$. Therefore, the mean difference between the pre-test and post-test stages was not significantly different. Because the significance level was less than 0.05 , the average preparedness scores in the pre-test and post-test stages were significantly different (Table 4).

\section{Discussion}

This study aimed to investigate the effect of an educational intervention on the knowledge, attitude, and skill of health care providers. The results showed that the Mean \pm SD score of knowledge, attitude, performance, and preparedness of health care providers was $7.25 \pm 1.72,10.50 \pm 1.31$, $32.78 \pm 4.55$, and $34.76 \pm 2.93$ for pre-test, and $5.49 \pm 3.15$, $5.83 \pm 2.98,45.52 \pm 6.5$, and $51.1 \pm 4.57$ for posttest before and after the intervention, respectively. There was a significant difference between the mean scores before and after the training in terms of knowledge, attitude, and preparedness $(\mathrm{P}<0.05)$, but no significant difference was observed between the mean scores of performance $(\mathrm{P}>0.05)$.

Accordingly, we found that the average score of knowledge after the intervention increased by $27 \%$, which was significant. In other words, holding a training course was effective in increasing the knowledge of health care providers. The mean scores of attitude showed a substantial increase of $4.95 \%$ in the post-test.

In terms of performance, the results showed that the mean performance scores of health care providers increased by $3.45 \%$ after the training course. However, there was no significant difference between the mean performance scores in the pre-test and post-test.

The preparedness score consisted of the total scores of knowledge, attitude, and the performance had a significant increase of $9 \%$ compared with that before the intervention. The results of various studies have confirmed the effect of the training course on the level of disaster preparedness. Ebrahimi et al. assessed the impact of implementing interventions on improving safety and health at the workplace in an oil company in Iran (2010-2015). Their results indicated the training course's effectiveness in increasing the readiness and safety of employees in the workplace and reducing work-related accidents and damages. Therefore, training is useful in preventing many accidents and crises or minimizing injuries [29]. Wiesner et al. evaluated the effect of education on medical students' knowledge and showed that educational intervention significantly affects students' preparedness [30]. Also, Nakhaei et al. showed that holding a training course effectively increases nurses' preparedness for disasters [20].

Parra Cotanda et al. investigated the effect of disaster preparedness training programs on staff in the emergency department of Barcelona Hospital. They showed that a training course significantly increased the knowledge of the staff. Still, their performance showed no significant change 6 months after the intervention [23], which is in line with the present study. This observation indicated that to improve the people's performance, more training, long-term planning, other incentives, and changes in the type of intervention are needed.

Khankeh et al. also studied the effect of earthquake coping training on male students on household readiness in Eshtehard City, Iran. Their results indicated the impact of educational intervention on improving and promoting people's attitudes [31]. Habte et al. conducted a study entitled "Assessment of knowledge, attitude, and practice of disaster preparedness among Tikur Anbessa Specialized Hospital health care workers, Addis Ababa, Ethiopia." They reported that the general attitude of about $64 \%$ of the respondents was optimistic about the subject [32]. The results of the present study, like the results of the above studies, emphasize the effect of education on creating a positive attitude.

A few studies have been conducted on the inconsistent attitude with the present study results, which may be due to differences in the statistical population or the method of intervention. For example, Ahmadzadeh et al. investigated the effect of earthquake preparedness training on 10-year-old male students and their families' awareness in Gorgan City, Iran. Their results showed a significant difference in their knowledge and skills while facing accidents and disasters before and after the intervention. However, there was no significant difference in attitude, which is inconsistent with the present study results. There was also a significant difference between the components of awareness of safe places in the earthquake, understanding of dangerous places in the earthquake, and necessary measures during the earthquake before and after the intervention. They concluded that educating students can increase the awareness and preparedness of the students and their families [7]. Mirzaei et al. in a study conducted on nurses at Shahid Rahnamoon Hospital in Yazd City, Iran, showed that holding a disaster management training course has a significant effect on increasing the knowledge and attitude of the subjects. However, in terms of performance, it was inconsistent 
with the results of the present study [33]. This discrepancy may be due to differences in the intervention method.

Najafi et al. also conducted a study on 60 nurses to examine disaster preparedness training through cyberspace on the knowledge and attitudes of individuals. A significant increase in the intervention group's knowledge score compared with the control group indicated the effectiveness of the educational intervention on the knowledge of individuals [34].

In general, various studies have been conducted worldwide to examine the preparedness of individuals and organizations against disasters from different aspects. Their statistical population and the target group were different, and there are few studies similar in the study method and the target group. However, most studies emphasize the effect of educational intervention on people's preparedness.

\section{Conclusion}

Our findings showed that the intervention had the greatest impact on knowledge and an improved attitude. The level of knowledge and attitude of individuals after the educational intervention increased significantly, and regarding performance, the mean scores of the respondents were at a low level. Although the increase in mean performance scores after the intervention was not significant, considering the descriptive results, it was found that by continuing the training, the people's performance can also be improved.

Overall, the findings showed that education increases the preparedness of health care providers against disasters because health care providers are responsible for educating the affected families. Increasing their preparedness can improve the preparedness of the covered households and thus reduce the vulnerability of people in the community against natural disasters.

The literature review showed that few programs had been used to train this group and the available programs are mostly short-term skills training programs, and longterm disaster management issues have received less attention. Therefore, it is recommended that disaster preparedness programs be part of one of the main topics of in-service training for health care providers and as one of the obligatory topics of education courses. In this regard, paying attention to educational programs is not sufficient, and maneuvers and exercises are also recommended.

\section{Ethical Considerations}

\section{Compliance with ethical guidelines}

This article was approved by the Ethics Committee of Isfahan University of Medical Sciences (IR.MUI.RESEARCH.REC.397256 on,1397.058 on 07/22/2018). After explaining the research process and obtaining their consent, the goals, importance, and necessity of conducting the research were described. A written consent was obtained from the participants, and the samples were assured that the information was confidential.

\section{Funding}

This research was financially supported by the ViceChancellor for Research and Technology of Isfahan University of Medical Sciences.

\section{Authors' contributions}

All authors were involved in the preparation of this article.

\section{Conflict of interest}

The authors had no conflict of interest.

\section{Acknowledgments}

We are thankful to the Isfahan University of Medical Sciences and all participants and individuals who assisted in this research.

\section{References}

[1] Ebrahiminejad M, Sadeghi Z. [Investigation of the relationship between preparedness and organizational resilience when facing earthquake (case study: Medical sciences university hospitals in Kerman) (Persian)]. Disaster Prevention and Management Knowledge (Quarterly). 2017; 6(4):358-67. http://dpmk.ir/article-1-101-en.html

[2] Karami A, Dargahi A, Farrokhi M, Poursadeghian M, Ivanbagha R, Mostafaei $\mathrm{P}$, et al. Studying the environmental health condition of the cities in the Kermanshah Province affected by 2017 earthquake. Health in Emergencies and Disasters. 2018; 4(1):29-36. [DOI:10.32598/hdq.4.1.29]

[3] Ezhilarasi MN, Jothy K. Knowledge of disaster preparedness and management among nurses in the disaster prone areas of Kerala. International Journal of Innovative Studies in Sociology and Humanities. 2018; 3(11):61-70. https://ijissh. org/storage/Volume3/Issue11/IJISSH-031108.pdf 
[4] Zarghami S, Teimuri A, Mohammadin H, Sabaei A. [Measuring and evaluating urban neighborhood's resilience against earthquake: The case of Zanjan downtown (Persian)]. Journal of Research and Urban Planning. 2016; 7(27):78-92. http:// jupm.miau.ac.ir/article_2140.html?lang=en

[5] Our World in Date. Natural disasters [Internet]. 2019 [Updated 2020]. Available from: https://ourworldindata.org/ natural-disasters

[6] Centre for Research on the Epidemiology of Disasters - CRED, Natural disasters [Internet]. 2019 [Updated 2020]. Available from: https://www.cred.be/publications

[7] Ahmadzadeh M. The effect of earthquake coping training on 10-year-old male students on their readiness level and their families in Gorgan [PhD. dissertation]. Tehran: University of Social Welfare and Rehabilitation Sciences; 2014. http:/ / uswr. ac.ir $/$ index.jsp?fkeyid=\&siteid $=1 \&$ pageid $=4369$

[8] Eslami A, Hassani N. [Application future research to manage risk by dividing earthquake return period of the future (Case Study: Earthquake Rey) (Persian)]. Disaster Prevention and Management Knowledge (Quarterly). 2016; 6(1):47-58. http:/ / dpmk.ir/article-1-51-en.html

[9] Dargahi A, Farrokhi M, Poursadeghiyan M, Ahagh MM, Karami A. Evaluation of functional preparedness and non structural safety of different health units of Kermanshah University of Medical Sciences in coping with natural disasters. Health in Emergencies and Disasters. 2017; 2(4):201-6. [DOI:10.29252/ nrip.hdq.2.4.201]

[10] Seyedin H, Dolatabadi ZA, Rajabifard F. Emergency nurses' requirements for disaster preparedness. Trauma Monthly. 2015; 20(4):e29033. [DOI:10.5812/traumamon.29033] [PMID] [PMCID]

[11] Ardalan A, Rajaei MH, Masoumi G, Azin A, Zonoobi V, Sarvar M, et al. 2012-2025 Roadmap of I.R.Iran's Disaster Health Management. PLoS Currents. 2012; 4:e4f93005fbcb34. [DOI:10.1371/4f93005fbcb34] [PMID] [PMCID]

[12] Piran P, Asadi S, Dadgar N. [Social resilience in reconstruction process (aase study: Darb-e-Astaneh and Baba Pashman Villages after the 1385 Lorestan, Silakhor Earthquake) (Petsian)]. Journal of Housing and Rural Environment. 2017; 36 (157):87-100. http://jhre.ir/article-1-1140-fa.html

[13] Ganjehi S, Omidvar B, Malekmohammadi B, Norouzi Kh. Analysis and modeling of safety parameters for selection of optimal routes in emergency after an earthquake: Case of $13^{\text {th }}$ aban neighorhood in Tehran. Health in Emergencies and Disasters. 2013; 1(1):60-76. http://hdq.uswr.ac.ir/files/site1/ user_files_990b99/eng/ganjehi-A-10-31-1-9e9d145.pdf

[14] Zandi B, Sarmadi MR, Karimi N. Educational needs of Tehran citizens towards the earthquake. Quarterly Journal of Environmental Education and Sustainable Development. 5(1):4152. http://ee.journals.pnu.ac.ir/article_3227.html

[15] Khankeh H, Mohhamadi R, Ahmadi F. Facilitatorand barrier factor for health services in natural disaster. Archives of Rehabilitation. 2006; 6(1):23-30. http://rehabilitationj.uswr. ac.ir/article-1-96-en.html

[16] Vishal S, Shital W, Joshi SG. Knowledge and attitude regarding disaster preparedness among the health careteam members in selected hospitals of Pune City. International Journal of Scientific Research and Management. 2016; 7(5):11251-7. https:/ / www.recentscientific.com/sites/default/files/5365_0.pdf
[17] Dargahi A, Bagheri S, Poursadeghiyan M, Hosseini Ahagh MM, Farrokhi M. Knowledge and attitudes of students in khalkhal medical sciences faculty on health actions in emergencies. Health in Emergencies and Disasters. 2017; 3(1):51-56 [DOI:10.29252/nrip.hdq.3.1.51]

[18] WHO. Risk reduction and emergency preparedness: WHO six-year strategy for the health sector and capacity development. Geneva: World Health Organization; 2007. https:// apps.who.int/iris/handle/10665/43736

[19] Kamal A, Songwathana P, Sia WS. Knowledge and skills of emergency care during disaster for community health volunteers: A literature review. Nurse Media Journal of Nursing. 2012; 2(2):371-81. [DOI: 10.14710/nmjn.v2i2.3970]

[20] Nakhaei M, Sh ST, Saadatjou SA, SabzehKar FA. [The effect of educational intervention on nurses' preparedness in emergencies and disasters (Persian)]. Journal of Birjand University of Medical Sciences. 2019; 26(3):237-48. [DOI:10.32592/ JBirjandUnivMedSci.2019.26.3.105]

[21] Ghoudarzi H, Vameghi R, Hosseini Fouladi S, Khammar A, Poursadeqiyan M, Kavari SH. Relationship between health and safety management status and job satisfaction among employees of rehabilitation centers with crisis management approach in Kohgiluyeh and Boyer-Ahmad Province. Health in Emergencies and Disasters. 2019; 4(4):193-200. [DOI:10.32598/ hdq.4.4.193]

[22] Rezaei T, Shirgol A, Taherian S, Kianian Gh, Ghasemkhani M. Education of disasters to families and its impact on their preparedness for natural disasters in Marand 2018. Paper presented at: the $9^{\text {th }}$ International Health Congress on Disasters and Disasters. 25-27 June 2019; Tehran. Royan Peugeo.

[23] Cotanda CP, Martínez MR, de la Maza VT, Cubells CL. Impact of a disaster preparedness training programme on health staff. Anales de Pediatría (English Edition). 2016; 85(3):149-54 [DOI:10.1016/j.anpede.2015.07.040]

[24] Torani S, Majd PM, Maroufi SS, Dowlati M, Sheikhi RA. The importance of education on disasters and emergencies: A review article. Journal of Education and Health Promotion. 2019; 8:85. [DOI:10.4103/jehp.jehp_262_18] [PMID] [PMCID]

[25] Farajzadeh M, Ghanei Gheshlagh R, Beiramijam M, Dalvand S, Ghawsi S, Amini H. Preparedness of nurses for crises and disasters in imam Khomeini and social security hospitals of Saqqez. Health in Emergencies and Disasters. 2017; 3(1):5763. [DOI:10.29252/NRIP.HDQ.3.1.57]

[26] Ghanbari V, Maddah SS, Khankeh HR, Karimloo M. [The effect of a disaster nursing education program on nurses' preparedness for responding to probable natural disasters (Persian)]. Iran Journal of nursing. 2011; 24(73):72-80. http://ijn.iums. ac.ir/article-1-1048-en.pdf

[27] Nadimi A, Ahmadi S, Zohouri F, Golbagh M. Inverted flower-like structure in Ramsheh region (northeast of Zagros mountain). Journal of Geotechnical Geology Quarterly. 2010; 6(3):217-24. https://www.sid.ir/en/Journal/ViewPaper. aspx?ID=202293

[28] Kwak SG, Kim JH. Central limit theorem: The cornerstone of modern statistics. Korean Journal of Anesthesiology. 2017; 70(2):144-56. [DOI:10.4097/kjae.2017.70.2.144] [PMID] [PMCID]

[29] Ebrahimi MH, Abbasi M, Khandan M, Poursadeghiyan M, Hami M, Biglari H. Effects of administrative interventions on 
improvement of safety and health in workplace: A case study in an oil company in Iran (2011-2015). Journal of Engineering and Applied Sciences. 2016; 11(3):346-51. [DOI:10.36478/ jeasci.2016.346.351]

[30] Wiesner L, Kappler S, Shuster A, DeLuca M, Ott J, Glasser E. Disaster training in 24 hours: Evaluation of a novel medical student curriculum in disaster medicine. Journal of Emergency Medicine. 2018; 54(3):348-53. [DOI:10.1016/j.jemermed.2017.12.008] [PMID]

[31] Khankeh H, Amanat N, Hosseini MA, Mohammadi F, Sadeghi A, Aghighi A. [The effect of earthquake preparedness training to male high school students on families (Persian)]. Journal of Rescue and Relief. 2013; 5(3):39-27. http:/ /jorar.ir/ article-1-163-en.html

[32] Habte A, Addisie A, Azazh A. Assessment of knowledge, attitude and practice of disaster preparedness among Tikur Anbessa specialized hospital health care workers, Addis Ababa, Ethiopia. American Journal of Nursing Science. 2018; 7(1):39-48. [DOI:10.11648/j.ajns.20180701.15]

[33] Mirzaei S, Eftekhari A, Sadeghian MR, Kazemi S, Nadjarzadeh $\mathrm{A}$. The effect of disaster management training program on knowledge, attitude, and practice of hospital staffs in natural disasters. Journal of Disaster \& Emergency Research. 2019; 2(1):9-16. [DOI:10.18502/jder.v2i1.566]

[34] Ghezeljeh TN, Aliha JM, Haghani H, Javadi N. Effect of education using the virtual social network on the knowledge and attitude of emergency nurses of disaster preparedness: A quasi-experiment study. Nurse Education Today. 2019; 73:88-93. [DOI:10.1016/j.nedt.2018.12.001] [PMID] 